\title{
Patterns and Prevalence of BRCAI and BRCA2 Germline Mutations Among Patients with Triple-Negative Breast Cancer: Regional Perspectives
}

\author{
Hikmat Abdel-Razeq (D) ${ }^{1,2}$ \\ Faris Tamimi (D) \\ Lama Abujamous ${ }^{3}$ \\ Sara Edaily' \\ Mahmoud Abunasser (D) \\ Rayan Bater' \\ Osama Salama' \\ 'Department of Internal Medicine, King \\ Hussein Cancer Center, Amman, Jordan; \\ ${ }^{2}$ Department of Internal Medicine, \\ School of Medicine, University of Jordan, \\ Amman, Jordan; ${ }^{3}$ Department of Cell \\ Therapy \& Applied Genomic, King \\ Hussein Cancer Center, Amman, Jordan
}

Correspondence: Hikmat Abdel-Razeq Department of Internal Medicine, King Hussein Cancer Center, Queen Rania Al Abdullah Street, P.O. Box: 1269, Amman, II94I, Jordan

Tel +962-65300460, Ext: 1000

Email habdelrazeq@khcc.jo
Background: Among all subtypes, patients with triple-negative (TN) breast cancer is known for their poor outcome and their higher risk of harboring BRCA1 or BRCA2 pathogenic mutations. Identification of such mutations has clinical impact on breast and ovarian cancer prevention and treatment decisions. We here report on patterns and prevalence of BRCA1 and BRCA2 mutations among Arab patients diagnosed with TN subtype.

Patients and Methods: Patients with TN-breast cancer $(n=197)$ were enrolled regardless of their age or family history. Following a detailed genetic counseling, BRCA1/2 testing was performed at reference labs. BRCA1 and BRCA2 variants were classified as negative, pathogenic/likely pathogenic (positive) and variants of uncertain significance (VUS).

Results: Median age of enrolled patients was 42 (range, 19-74) years and 27 (13.7\%) were non-Jordanian Arabs. Among the study group, 50 (25.4\%) were tested positive for BRCA1 $(\mathrm{n}=36,18.3 \%)$ or BRCA2 ( $\mathrm{n}=14,7.1 \%)$, while 14 (7.1\%) others had VUS. Compared to older ones, mutation rates were higher among patients $<40$ years $(32.9 \%, \mathrm{P}=0.034)$, those with close relatives with breast, ovarian, pancreatic or prostate cancer $(37.8 \%, \mathrm{P}=0.002)$ and those with two or more breast cancers $(41.4 \%, \mathrm{P}=0.032)$. Among eligible patients, 23 (63.9\%) patients underwent prophylactic mastectomy, while 19 (52.8\%) patients had risk-reducing salpingo-oophorectomy. None of the patients with VUS underwent any prophylactic surgery. Conclusion: Arab patients with TN-breast cancer have relatively high BRCA1 or BRCA2 mutation rates. Young age at diagnosis and personal and family history of breast cancer further increase this risk.

Keywords: cancer genetics, genetic consultation, genetic variants, women's cancer, breast cancer, BRCA1/2 mutation

\section{Introduction}

Breast cancer is the most common cancer worldwide and, in our region, too. ${ }^{1,2}$ Triple-negative breast cancer (TNBC) is a subgroup that are negative for the estrogen (ER), progesterone (PR) and human epidermal growth factor-2 (HER2) receptors, account for $10-20 \%$ of all breast cancers and are more common in younger patients and in certain ethnic groups. ${ }^{3,4}$ Among all breast cancer subtypes, TNBC is usually associated with the worst outcome. ${ }^{5}$

Majority of breast cancer cases are sporadic; however, 5-10\% of cases are hereditary and mostly related to mutations in BRCA1 or BRCA2 genes; both are 
cancer susceptibility genes that are part of the deoxyribonucleic acid (DNA) repair pathway. ${ }^{6}$ A large proportion of tumors in women with BRCA1 mutation exhibits a triplenegative phenotype. ${ }^{7}$

Depending on age at diagnosis and personal and family history of cancer, women may undergo genetic counseling and genetic testing. Breast cancer histology is not, by itself, an indication for testing. However, TNBC as a particular subtype, is commonly tested. ${ }^{8,9}$ Because of higher risk for BRCA1/2 mutations, the National Comprehensive Cancer Network (NCCN) guidelines recommend genetic counseling and testing for all women aged 60 years or younger with TNBC. ${ }^{10}$

Several studies have reported that up to $20 \%$ of women with TNBC breast cancer may carry BRCA1 or BRCA2 mutations. ${ }^{11-16}$ Pathogenic mutations in both genes confer a high risk of both breast and ovarian cancers. ${ }^{17,18}$ So, identification of carriers is extremely important and should be actively sought in high-risk patients. Risk-reduction interventions, like bilateral mastectomies and oophorectomies are highly recommended for patients with $B R C A 1$ or $B R C A 2$ mutation carriers, especially so among younger patients. ${ }^{19,20}$

Identification of mutation carriers among patients actively treated for breast or ovarian cancers may have therapeutic implications, too. Recent data have suggested that patients with advanced-stage TNBC associated with BRCA1 or BRCA2 mutations may benefit from specific drugs like PARP (poly ADP ribose polymerase) inhibitors; both olaparib and talazoparib are currently approved for such situation. ${ }^{21-23}$ Additionally, there is some evidence that adding platinum-agents in the neoadjuvant setting improves the pathologic complete response. ${ }^{24-26}$

The aim of our study is to define the pattern and prevalence of germline BRCA1 and BRCA2 mutations among Arab patients; Jordanian in particular, with TNBC diagnosed, treated and followed at our institution regardless of their family or personal history of breast or ovarian cancer.

\section{Patients and Methods}

We utilized our database of all breast cancer patients tested as per the NCCN guidelines for BRCA1/2 mutations $(n=1437)$. Patients with no expression of ER or PR receptors and negative for HER2 (triple-negative) were identified regardless of their personal or family history of cancer. Human epidermal growth factor receptor-2 (HER2) was tested using immune histochemical staining (IHC) and tumor cells were considered positive with +3 staining, negative with scores of 0 or +1 while those with +2 scores were considered equivocal, for which fluorescence in situ hybridization (FISH) was performed. ${ }^{27}$ ER or PR were defined as positive if tumor cell nuclei staining is $\geq 1 \%$. Clinical and pathological characteristics of the tumors were obtained from patients' electronic medical records. A detailed 3-generation family history was obtained by one of the investigators or by a genetic counselor. Genetic testing and counseling were done at no cost to participants as part of our routine clinical practice. DNA extraction and purification were done on peripheral blood samples at our molecular laboratory. The extraction method was performed using DNA kits (Gentra PureGene Blood Kit (Qiagen) or EZ1 Advanced XL which performs fully automated DNA purification of samples using magnetic particles). BRCA1/2 testing was performed at 3 reference labs; invitae (San Francisco, CA, USA), Leeds Cancer Center (Leeds, United Kingdom) and Myriad Genetics laboratory (Salt Lake City, UT, USA). Full-gene sequencing and deletion/duplication analysis were carried out using nextgeneration sequencing (NGS) technology and confirmatory sequencing was performed by Sanger sequencing. Exonic deletions and duplications were called using multiplex ligation-dependent probe amplification (MLPA) dosage analysis by using P087, P045, and P260 or using an in-house algorithm that determines copy number by comparing the read depth for each target in the proband sequence.

BRCA1 and BRCA2 mutations were classified as benign or likely benign variants (negative), pathogenic or likely pathogenic variants (positive) and variants of uncertain significance (VUS).

The study was conducted in accordance with the local and international guidelines and regulations on human research including the 1964 Helsinki declaration and its later amendments. The study was approved by our Institutional Review Board (IRB) and all patients signed informed consent.

\section{Statistical Analysis}

Clinical and pathologic characteristics of patients enrolled were collected, tabulated and described by percentages, ranges or medians. Related family members diagnosed with breast cancer who underwent genetic testing after the index case in the family were excluded. Chi-square tests were used to compare the proportion of BRCAl and $B R C A 2$ pathogenic/likely pathogenic mutation carriers according to age $(<40$ versus $\geq 40$ years $)$ and personal 
history or family history of cancer; a P-value of 0.05 was considered significant.

We also compared the disease-free survival (DFS) and overall survival (OS) among the patients with mutation carriers and those without. DFS was defined as the time from the date of diagnosis to the date of first occurrence of local recurrence (breast or axilla), development of contralateral or ipsilateral breast cancer including ductal carcinoma in situ (DCIS) but not lobular carcinoma in situ (LCIS), distant metastasis, or death by any cause without evidence of disease, while OS was defined as the time from date of diagnosis until the date of death from any cause. Cancer survival probabilities were estimated using Kaplan-Meier curves using GraphPad PRISM version 6.0 for Windows (GraphPad Software, La Jolla California USA). Comparisons of survival times were performed using the Log rank test; a significance criterion of $\mathrm{P}<0.05$ was used for the analysis. SAS software version 9.4 (SAS Institute Inc., Cary, NC) was used to estimate survival rates and perform the Log rank test.

\section{Results}

\section{Patients Characteristics}

During the 3-year study period, genetic counseling and testing were performed for a total of 1437 patients with breast cancer who fulfilled the NCCN guidelines; 197 $(13.7 \%)$ of them had triple negative disease and were the focus of this report. Median age at diagnosis (range) was 42 (19-74) years with 85 (43.1\%) were younger than 40 years. Majority of the patients $(\mathrm{n}=171,86.8 \%)$ had invasive ductal carcinoma (IDC) and $13(6.6 \%)$ had de novo metastatic disease. Jordanians $(n=170,86.3 \%)$ constitute the majority, while the other $27(13.7 \%)$ patients were from Palestine, Syria, Libya, and Iraq. Except for one, all patients were females; patients' characteristics are summarized in Table 1.

\section{Genetic Testing}

Among the study group, a total of $50(25.4 \%)$ were tested positive for BRCA1 $(\mathrm{n}=36,18.3 \%)$ or BRCA2 $(\mathrm{n}=14$, $7.1 \%)$ while 14 (7.1\%) others had VUS. Among 85 patients diagnosed with triple-negative disease at age $<40$ years, BRCA1/2 mutations were detected in $28(32.9 \%)$, compared to $22(19.6 \%)$ among 112 older ones, $\mathrm{P}=0.034$. Mutation rate was higher $(\mathrm{n}=12,41.4 \%)$ among a group of 29 patients who were personally diagnosed with two or more breast cancers (at any age) compared to a rate of
Table I Patient Demographics and Baseline Characteristics $(n=197)$

\begin{tabular}{|c|c|c|c|}
\hline \multicolumn{2}{|l|}{ Characteristics } & Number & (\%) \\
\hline \multirow[t]{2}{*}{ Age at diagnosis (years) } & Median & \multicolumn{2}{|l|}{42} \\
\hline & Range & \multicolumn{2}{|c|}{ 19-74 } \\
\hline \multirow{5}{*}{$\begin{array}{l}\text { Age group at diagnosis } \\
\text { (years) }\end{array}$} & $<30$ & 17 & 8.6 \\
\hline & $30-39$ & 68 & 34.5 \\
\hline & $40-49$ & 66 & 33.5 \\
\hline & $50-59$ & 38 & 19.3 \\
\hline & $>60$ & 8 & 4.1 \\
\hline \multirow[t]{2}{*}{ Nationality } & Jordanian & 170 & 86.3 \\
\hline & Others & 27 & 13.7 \\
\hline \multirow[t]{2}{*}{ Pathology } & $\begin{array}{l}\text { Invasive ductal } \\
\text { carcinoma }\end{array}$ & $|7|$ & 86.8 \\
\hline & Other & 26 & 13.2 \\
\hline \multirow[t]{3}{*}{ Grade } & I, II & 42 & 21.3 \\
\hline & III & 134 & 68.0 \\
\hline & NA & 21 & 10.7 \\
\hline \multirow[t]{2}{*}{ Stage } & Early stage & 184 & 93.4 \\
\hline & Metastatic & 13 & 6.6 \\
\hline
\end{tabular}

$22.6 \%(\mathrm{n}=38)$ of the 168 others who had one personal history of breast cancer, $p=0.032$. Additionally, pathogenic/likely pathogenic BRCA1/2 variants were significantly higher $(\mathrm{n}=28,37.8 \%)$ among 74 patients with triple-negative disease who had one or more close relatives (first-, second- or third-degree) with breast, pancreatic, or prostate cancer (Gleason score $\geq 7$ ), compared to a rate of $17.9 \%$ among a group of 123 patients without family history, $\mathrm{p}=0.002$. Rates, however, were not different among Jordanians (24.1\%) versus non-Jordanians $(33.3 \%), p=0.307$. Results of genetic testing are summarized in Table 2. Details of all identified mutations in $B R C A 1$ and BRCA2 (pathogenic, likely pathogenic and VUS) are summarized in Tables $\mathrm{S} 1-\mathrm{S} 3$.

\section{Outcome}

One of the patients diagnosed with pathogenic variants had de novo metastatic disease while 7 (14.0\%) others had bilateral breast cancer on presentation. Six (12.0\%) patients returned to their home countries to be followed 
Table 2 BRCAI/2 Pathogenic Mutation Rates by Subgroups

\begin{tabular}{|c|c|c|c|c|}
\hline \multicolumn{2}{|l|}{ Characteristics } & $\begin{array}{l}\text { Number of } \\
\text { Patients }\end{array}$ & $\begin{array}{l}\text { BRCAII } \\
\text { BRCA2 } \\
\text { n (\%) }\end{array}$ & P-value \\
\hline \multirow[t]{2}{*}{ Age at diagnosis (years) } & $<40$ & 85 & $28(32.9 \%)$ & \multirow[t]{2}{*}{0.034} \\
\hline & $\geq 40$ & 112 & $22(19.6 \%)$ & \\
\hline \multirow{2}{*}{$\begin{array}{l}\text { Diagnosed at any age with two or more diagnoses of breast cancer at any age } \\
\text { (synchronously or asynchronously) }\end{array}$} & Yes & 29 & $12(4 \mid .4)$ & \multirow[t]{2}{*}{0.032} \\
\hline & No & 168 & $38(22.6)$ & \\
\hline \multirow{2}{*}{$\begin{array}{l}\text { Diagnosed at age } 50 \text { years or younger with: I or more close relatives with breast cancer } \\
\text { at any age, I or more close relatives with pancreatic cancer, or I or more close relatives } \\
\text { with prostate cancer (Gleason score } \geq 7 \text { ) }\end{array}$} & Yes & 74 & $28(37.8)$ & \multirow[t]{2}{*}{0.002} \\
\hline & No & 123 & $22(17.9)$ & \\
\hline \multirow{2}{*}{$\begin{array}{l}\text { Diagnosed at any age with I or more close relatives with breast cancer diagnosed at age } \\
50 \text { years or younger }\end{array}$} & Yes & 47 & $19(40.4)$ & \multirow[t]{2}{*}{0.007} \\
\hline & No & 150 & 31 (20.7) & \\
\hline \multirow[t]{2}{*}{ Nationality } & Jordanian & 170 & $4 I(24 . I)$ & \multirow[t]{2}{*}{0.307} \\
\hline & Others & 27 & $9(33.3)$ & \\
\hline
\end{tabular}

there; all had extensive counseling and were aware of their genetic testing results and its implications. Among the remaining 36 patients, 23 (63.9\%) patients underwent prophylactic mastectomy at the time of the primary breast cancer surgery while 19 (52.8\%) patients had risk-reducing salpingo-oophorectomy. None of the patients with VUS had any risk-reducing surgery.

At a median follow-up of 21 (range, 2-60) months, 6 $(12.0 \%)$ patients developed distal metastases. However, no differences were found in the rate of DFS ( $81.6 \%$ versus $86.7 \% ; p=0.94$, Figure 1$)$ or OS $(92.5 \%$ versus $92.0 \%$; $\mathrm{p}=0.65$, Figure 2 ) in patients with pathogenic/likely pathogenic BRCA1/2 variants versus patients without, respectively. During the follow up, 3 (23.1\%) of the 13 patients who did not have prophylactic mastectomy developed contralateral breast cancer, compared to none among the 23 patients who underwent prophylactic mastectomy.

\section{Discussion}

Given the high penetrance rate of BRCA1/2 mutations, genetic counseling of family members is extremely important. ${ }^{28}$ Many cases of breast and ovarian cancer can be prevented if comprehensive genetic counseling programs are implemented to deal with patients and their family members.

Rates of pathogenic BRCA1/2 mutations differ by ethnicity. In one retrospective study conducted at Duke and UCSF that included a total of 450 evaluable patients with TNBC, 139 (30.8\%) had confirmed BRCA1 or BRCA2 mutations; rate was highest among Ashkenazi Jewish (50\%) and lowest among Hispanics (20\%). ${ }^{29}$ In another study from Korea, only $13.1 \%$ of 1628 women with TNBC treated at Samsung Medical Center (SMC), had BRCA1 or BRCA2 mutations. The mean age at diagnosis of mutation carriers was significantly younger than the non-carriers (45.6 vs 50.1 years, $\mathrm{p}<0.0001){ }^{30}$

Similar to many low- and middle-income countries, the median age at breast cancer diagnosis in Jordan is 52 years, which is 10 years younger than most Western societies. ${ }^{31-33}$ To enhance our knowledge about genetic variations associated with breast cancer and its contribution to "younger age at diagnosis" in our country and the region, we established a genetic testing and counseling program and teamed up with 3 international reference labs to initially test for BRCA1 and BRCA2 mutations and then expanded to test for more breast cancer predisposing genes. Through this program, and over the past few years, more than 1300 patients were already tested and initial results were reported earlier. ${ }^{34,35}$ Our mutation rates (11-14\%) were little higher than previously reported in neighboring Arab countries. ${ }^{36}$

Our rates of BRCA1/2 mutations in patients with triplenegative disease, mostly in $B R C A 1$, are similar to previously reported rates. ${ }^{37}$ However, our findings of positive pathogenic variants of $30-40 \%$ in special groups of TNBC worth emphasis. Such high rates were found among younger patients and those with positive family or personal history of breast cancer.

Though issues related to prognosis and treatment outcomes of BRCA1/2-carriers are not settled, many studies had shown 


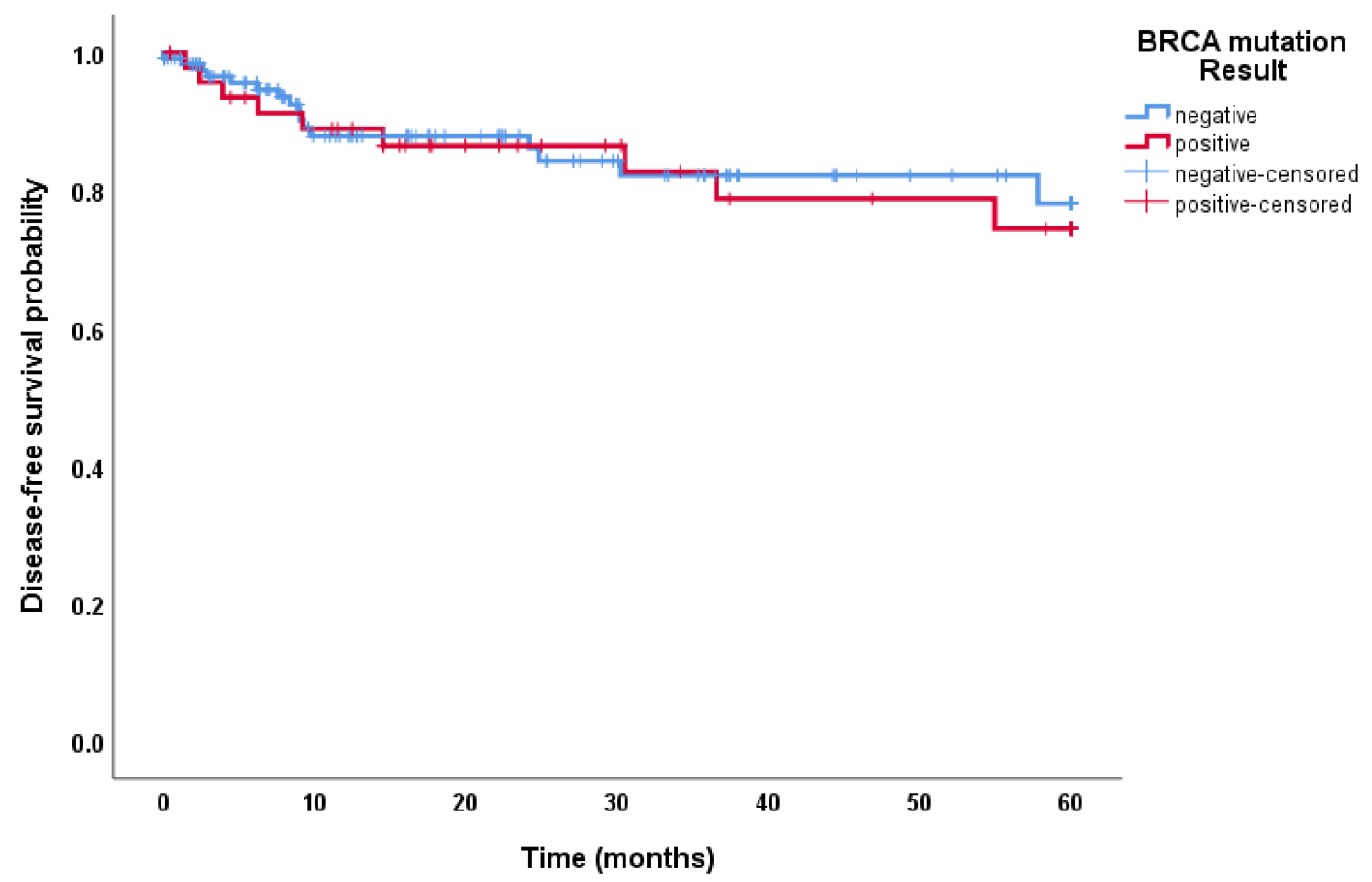

\begin{tabular}{|c|c|c|c|c|c|c|c|}
\hline \multicolumn{2}{|c|}{ Month } & $\mathbf{0}$ & $\mathbf{1 2}$ & $\mathbf{2 4}$ & $\mathbf{3 6}$ & $\mathbf{4 8}$ & $\mathbf{6 0}$ \\
\hline \multirow{2}{*}{$\begin{array}{c}\text { BRCA- } \\
\text { Negative }\end{array}$} & Patients & 135 & 71 & 49 & 35 & 23 & 18 \\
\cline { 2 - 8 } & Events & 0 & 12 & 12 & 15 & 15 & 16 \\
\hline \multirow{2}{*}{$\begin{array}{c}\text { BRCA- } \\
\text { Positive }\end{array}$} & Patients & 49 & 37 & 26 & 21 & 18 & 15 \\
\cline { 2 - 8 } & Events & 0 & 5 & 6 & 7 & 8 & 9 \\
\hline
\end{tabular}

Figure I Kaplan-Meier estimates of DFS: $81.6 \%$ in patients with positive BRCAI/2 mutation versus $86.7 \%$ in patients with no mutation, $\mathrm{P}=0.94$.

worse outcomes. A meta-analysis that included 60 studies and 3588 BRCA1 or BRCA2 mutation carriers among over 100,000 patients found that $B R C A 1$ mutation carriers had worse $\mathrm{OS}$ and worse breast cancer specific survival (BCSS) than noncarriers (hazard ratio, HR 1.30, 95\% CI: 1.11-1.52) and (HR 1.45, 95\% CI: 1.01-2.07), respectively. BRCA2 carriers, on the other hand, had similar OS but worse BCSS. ${ }^{38}$ Similar conclusions were reached by another Dutch hospital-Based study that looked, specifically, into young women who were BRCA1/2 mutation carriers and diagnosed with breast cancer before the age of $50 .{ }^{39}$ Such difference in survival can be attributed to second ovarian cancers, differences in tumor characteristics and its associated treatment response. Several other studies had reached similar conclusions. ${ }^{40}$ Things, however, may be different in TNBC; some studies had shown that BRCA1/2 mutation carriers with TNBC had better OS than noncarriers counterpart (HR 0.49, 95\% CI: 0.26-0.92) ${ }^{38}$ Better OS among BRCA1/2-carriers TNBC was also found in Cospen et al study, at least during the first 2 years of follow up; ( $95 \%$ [95\% CI 89 97] vs $91 \%$ [88-94]; HR 0.59 [95\% CI 0.35-0.99]; $\mathrm{p}=0 \cdot 047$ ) but not at 5 years or 10 years. ${ }^{37}$ In our study, such difference in OS could not be identified.

The concept of prophylactic mastectomy was acceptable to at least two-thirds of our patients with mutation carriers. Only 4 patients refused any prophylactic procedure and 9 others asked for more time to think about it. The fact that 3 (23.1\%) of these patients developed contralateral breast cancer should alert us to intensify our 


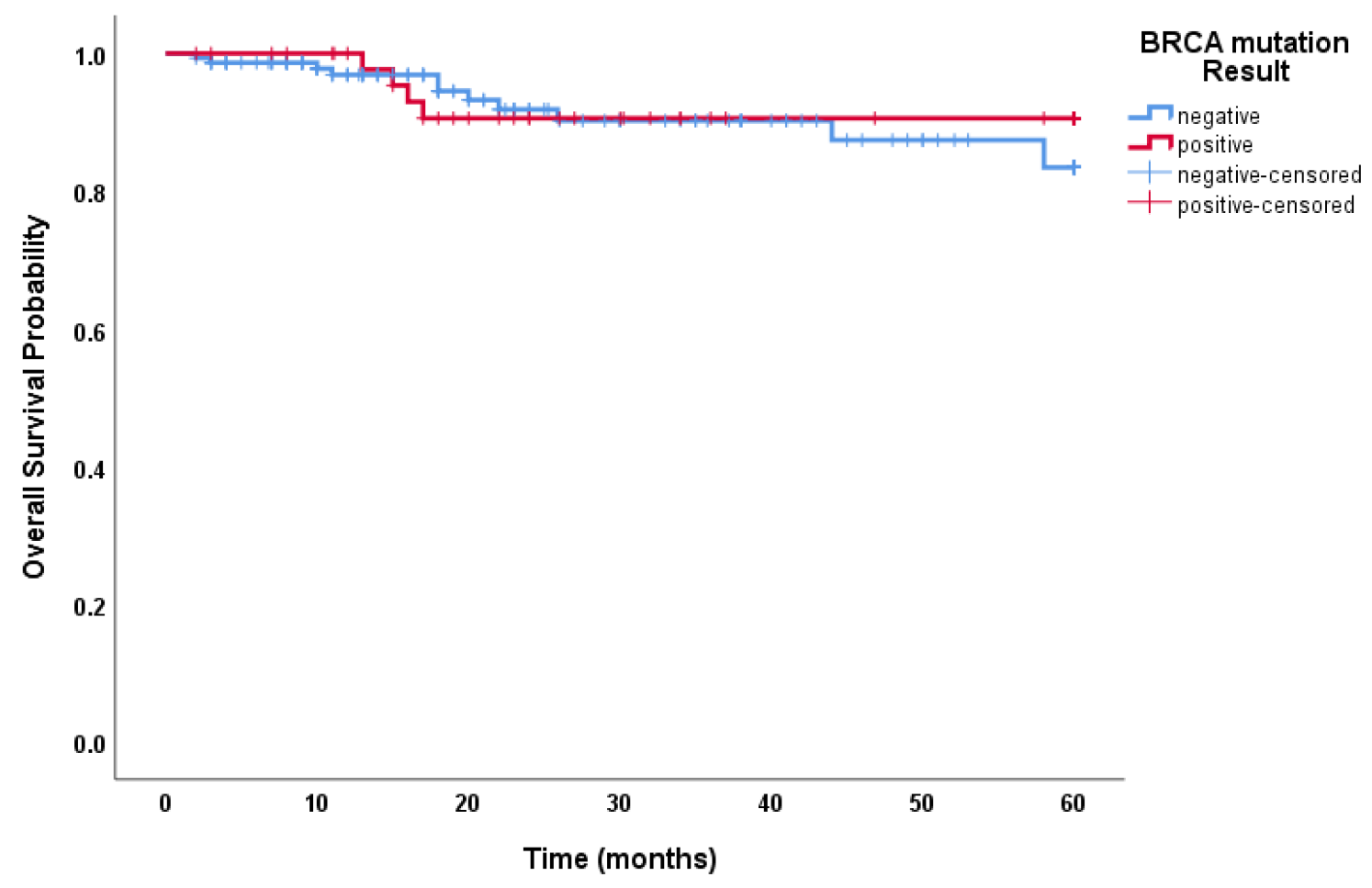

\begin{tabular}{|c|c|c|c|c|c|c|c|}
\hline \multicolumn{2}{|c|}{ Month } & $\mathbf{0}$ & $\mathbf{1 2}$ & $\mathbf{2 4}$ & $\mathbf{3 6}$ & $\mathbf{4 8}$ & $\mathbf{6 0}$ \\
\hline \multirow{2}{*}{$\begin{array}{c}\text { BRCA- } \\
\text { Negative }\end{array}$} & Patients & 147 & 102 & 58 & 42 & 28 & 20 \\
\cline { 2 - 8 } & Events & 0 & 4 & 8 & 9 & 10 & 11 \\
\hline \multirow{2}{*}{$\begin{array}{c}\text { BRCA- } \\
\text { Positive }\end{array}$} & Patients & 50 & 43 & 30 & 22 & 20 & 18 \\
\cline { 2 - 8 } & Events & 0 & 0 & 0 & 4 & 4 & 4 \\
\hline
\end{tabular}

Figure 2 Kaplan-Meier Estimates of OS: $92.5 \%$ in patients with positive BRCAI/2 mutation versus $92.0 \%$ in patients with no mutation, $\mathrm{P}=0.65$.

efforts to convince such patients how serious this issue can be. It is hoped that a stronger psychosocial program and patients' support groups would have a positive impact.

\section{Conclusions}

Arab patients with triple-negative breast cancer subtype have high BRCA1 or BRCA2 mutation rates. Young age and personal or family history of breast cancer in close relatives further increase this risk.

\section{Abbreviations}

BCSS, breast cancer specific survival; BRCA1/2, breast cancer susceptibility gene-1 and 2; DCIS, ductal carcinoma in situ; DFS, disease-free survival; DNA, deoxyribonucleic acid; ER, estrogen receptors; FISH, fluorescence in situ hybridization; HER2, human epidermal growth factor receptor-2; HR, hazard ratio; LCI, lobular carcinoma in situ; MLPA, multiplex ligationdependent probe amplification; NCCN, National Comprehensive Cancer Network; NGS, next-generation sequencing; OS, overall survival; PARP, poly(adenosine diphosphate)-ribose polymerase; $\mathrm{PR}$, progesterone receptors; TN, triple-negative; $\mathrm{TNBC}$, triple-negative breast cancer; VUS, variants of uncertain significance.

\section{Data Sharing Statement}

Data associated with this manuscript can be made available through the corresponding author based on reasonable requests.

\section{Ethics Approval}

The study was approved by the Institutional Review Board (IRB) at King Hussein Cancer Center, and all patients signed informed consent. 


\section{Consent to Participate}

Obtained and available.

\section{Consent for Publication}

Patients' data was deidentified, consent to publish is not mandated.

\section{Author Contributions}

All authors made a significant contribution to the work reported, whether that is in the conception, study design, execution, acquisition of data, analysis and interpretation, or in all these areas; took part in drafting, revising or critically reviewing the article; gave final approval of the version to be published; have agreed on the journal to which the article has been submitted; and agree to be accountable for all aspects of the work.

\section{Funding}

There is no funding to report.

\section{Disclosure}

The authors reported no conflicts of interest for this work.

\section{References}

1. Siegel RL, Miller KD, Fuchs HE, Jemal A. Cancer Statistics, 2021. CA Cancer J Clin. 2021;71(1):7-33. doi:10.3322/caac.21654

2. Torre LA, Islami F, Siegel RL, Ward EM, Jemal A. Global Cancer in Women: burden and Trends. Cancer Epidemiol Biomarkers Prev. 2017;26(4):444-457. doi:10.1158/1055-9965.EPI-16-0858

3. Trivers KF, Lund MJ, Porter PL, et al. The epidemiology of triple-negative breast cancer, including race. Cancer Causes Control. 2009;20:1071. doi:10.1007/s10552-009-9331-1

4. Dickens C, Duarte R, Zietsman A, et al. Racial comparison of receptor-defined breast cancer in Southern African women: subtype prevalence and age-incidence analysis of nationwide cancer registry data. Cancer Epidemiol Biomarkers Prev. 2014;23(11):2311-2321. doi:10.1158/1055-9965.EPI-14-0603

5. Haffty B, Yang Q, Reiss M, et al. Locoregional relapse and distant metastasis in conservatively managed triple negative early-stage breast cancer. $J$ Clin Oncol. 2006;24(36):5652-5657. doi:10.1200/ JCO.2006.06.5664

6. Larsen MJ, Thomassen M, Gerdes A-M, Kruse TA. Hereditary breast Cancer: clinical, pathological and molecular characteristics. Breast Cancer. 2014;8:145-155. doi:10.4137/BCBCR.S18715

7. Wong-Brown MW, Meldrum CJ, Carpenter JE, et al. Prevalence of BRCA1 and BRCA2 germline mutations in patients with triple-negative breast cancer. Breast Cancer Res Treat. 2015;150 (1):71-80. doi:10.1007/s10549-015-3293-7

8. Lakhani SR, Van De Vijver MJ, Jacquemier J, et al. The pathology of familial breast cancer: predictive value of immunohistochemical markers estrogen receptor, progesterone receptor, HER-2, and p53 in patients with mutations in BRCA1 and BRCA2. J Clin Oncol. 2002;20(9):2310-2318. doi:10.1200/JCO.2002.09.023
9. Robertson L, Hanson H, Seal S, et al. BRCA1 testing should be offered to individuals with triple-negative breast cancer diagnosed below 50 years. Br J Cancer. 2012;106(6):1234-1238. doi:10.1038/ bjc. 2012.31

10. NCCN Guidelines, Genetic/Familial high-risk assessment: breast, ovarian and pancreatic. Version 2.2021. Available from: https:// www.nccn.org/professionals/physician_gls/pdf/genetics_bop.pdf. Accessed 22 March 2021.

11. Gonzalez-Angulo AM, Timms KM, Liu S, et al. Incidence and outcome of BRCA mutations in unselected patients with triple receptor-negative breast cancer. Clin Cancer Res. 2011;17 (5):1082-1089. doi:10.1158/1078-0432.CCR-10-2560

12. Anglian Breast Cancer Study Group. Prevalence and penetrance of BRCA1 and BRCA2 mutations in a population-based series of breast cancer cases. Br J Cancer. 2000;83(10):1301-1308. doi:10.1054/ bjoc. 2000.1407

13. Peto J, Collins N, Barfoot R, et al. Prevalence of BRCA1 and BRCA2 gene mutations in patients with early-onset breast cancer. J Natl Cancer Inst. 1999;91(11):943-949. doi:10.1093/jnci/91.11.943

14. Hartman AR, Kaldate RR, Sailer LM, et al. Prevalence of BRCA mutations in an unselected population of triple-negative breast cancer. Cancer. 2012;118(11):2787-2795. doi:10.1002/cncr.26576

15. Fostira F, Tsitlaidou M, Papadimitriou C, et al. Prevalence of BRCA1 mutations among 403 women with triple-negative breast cancer: implications for genetic screening selection criteria: a Hellenic Cooperative Oncology Group Study. Breast Cancer Res Treat. 2012;134(1):353-362. doi:10.1007/s10549-012-2021-9

16. Young SR, Pilarski RT, Donenberg T, et al. The prevalence of BRCA1 mutations among young women with triple-negative breast cancer. BMC Cancer. 2009;9:86. doi:10.1186/1471-2407-9-86

17. Dite GS, Jenkins MA, Southey MC, et al. Familial risks, early-onset breast cancer, and BRCA1 and BRCA2 germline mutations. $J$ Natl Cancer Inst. 2003;95(6):448-457. doi:10.1093/jnci/95.6.448

18. Nathanson KL, Wooster R, Weber BL. Breast cancer genetics: what we know and what we need. Nat Med. 2001;7(5):552-556. doi: $10.1038 / 87876$

19. Rebbeck TR, Lynch HT, Neuhausen SL, et al.; Prevention and Observation of Surgical End Points Study Group. Prophylactic oophorectomy in carriers of BRCA1 or BRCA2 mutations. $N$ Engl J Med. 2002;346(21):1616-1622. doi:10.1056/NEJMoa012158.

20. Chai X, Friebel TM, Singer CF, et al. Use of risk-reducing surgeries in a prospective cohort of 1499 BRCA1 and BRCA2 mutation carriers. Breast Cancer Res Treat. 2014;148(2):397-406. doi:10.1007/s10549-014-3134-0

21. Turner NC, Telli ML, Rugo HS, et al. A Phase II Study of Talazoparib after Platinum or Cytotoxic Nonplatinum Regimens in Patients with Advanced Breast Cancer and Germline BRCA1/2 Mutations (ABRAZO). Clin Cancer Res. 2019;25(9):2717-2724. doi:10.1158/1078-0432.CCR-18-1891

22. Litton JK, Rugo HS, Ettl J, et al. Talazoparib in Patients with Advanced Breast Cancer and a Germline BRCA Mutation. $N$ Engl $J$ Med. 2018;379(8):753-763. doi:10.1056/NEJMoa1802905

23. Turk AA, Wisinski KB. PARP inhibitors in breast cancer: bringing synthetic lethality to the bedside. Cancer. 2018;124(12):2498-2506. doi: $10.1002 /$ cncr.31307

24. Garufi G, Palazzo A, Paris I, et al. Neoadjuvant therapy for triple-negative breast cancer: potential predictive biomarkers of activity and efficacy of platinum chemotherapy, PARP- and immune-checkpoint-inhibitors. Expert Opin Pharmacother. 2020;21 (6):687-699. doi:10.1080/14656566.2020.1724957

25. Fitzpatrick A, Tutt A. Controversial issues in the neoadjuvant treatment of triple-negative breast cancer. Ther Adv Med Oncol. 2019;11:1758835919882581. doi:10.1177/1758835919882581 
26. Garutti M, Pelizzari G, Bartoletti M, et al. Platinum Salts in Patients with Breast Cancer: a Focus on Predictive Factors. Int J Mol Sci. 2019;20(14):3390. doi:10.3390/ijms20143390

27. Taylor VJ, Barnes PJ, Godwin SC, Bethune GC. Assessment of HER2 using the 2018 ASCO/CAP guideline update for invasive breast cancer: a critical look at cases classified as HER2 2+ by immunohistochemistry. Virchows Arch. 2021. doi:10.1007/s00428021-03034-4

28. Kuchenbaecker KB, Hopper JL, Barnes DR, et al. Risks of Breast, Ovarian, and Contralateral Breast Cancer for BRCA1 and BRCA2 Mutation Carriers. JAMA. 2017;317(23):2402-2416. doi:10.1001/ jama.2017.7112

29. Greenup R, Buchanan A, Lorizio W, et al. Prevalence of BRCA mutations among women with triple-negative breast cancer (TNBC) in a genetic counseling cohort. Ann Surg Oncol. 2013;20 (10):3254-3258. doi:10.1245/s10434-013-3205-1

30. Ryu JM, Choi HJ, Kim I, et al. Prevalence and oncologic outcomes of BRCA 1/2 mutations in unselected triple-negative breast cancer patients in Korea. Breast Cancer Res Treat. 2019;173(2):385-395. doi:10.1007/s10549-018-5015-4

31. Bidoli E, Virdone S, Hamdi-Cherif M, et al. Worldwide Age at Onset of Female Breast Cancer: a 25-Year Population-Based Cancer Registry Study. Sci Rep. 2019;9(1):14111. doi:10.1038/s41598-01950680-5

32. Abdel-Razeq H, Mansour A, Jaddan D. Breast cancer care in Jordan. JCO Glob Oncol. 2020;6:260-268. doi:10.1200/JGO.19.00279

33. Johnson E. Breast cancer racial differences before age 40-implications for screening. J Nat Med Assoc. 2002;94:149-156.
34. Abdel-Razeq H, Al-Omari A, Zahran F, Arun B. Germline BRCA1/ BRCA2 mutations among high risk breast cancer patients in Jordan. BMC Cancer. 2018;18(1):152. doi:10.1186/s12885-018-4079-1

35. Abdel-Razeq H, Abujamous L, Jadaan D. Patterns and Prevalence of Germline BRCA1 and BRCA2 Mutations among High-Risk Breast Cancer Patients in Jordan: a Study of 500 Patients. J Oncol. 2020;2020:8362179. doi:10.1155/2020/8362179

36. El Saghir NS, Zgheib NK, Assi HA, et al. BRCA1 and BRCA2 mutations in ethnic Lebanese Arab women with high hereditary risk breast cancer. Oncologist. 2015;20(4):357-364. doi:10.1634/theoncologist.2014-0364

37. Copson ER, Maishman TC, Tapper WJ, et al. Germline BRCA mutation and outcome in young-onset breast cancer (POSH): a prospective cohort study. Lancet Oncol. 2018;19(2):169-180. doi:10.1016/S1470-2045(17)30891-4

38. Baretta Z, Mocellin S, Goldin E, Olopade OI, Huo D. Effect of BRCA germline mutations on breast cancer prognosis: a systematic review and meta-analysis. Medicine. 2016;95(40):e4975. doi:10.1097/MD.0000000000004975

39. Schmidt MK, van den Broek AJ, Tollenaar RA, et al. Breast Cancer Survival of BRCA1/BRCA2 Mutation Carriers in a Hospital-Based Cohort of Young Women. J Natl Cancer Inst. 2017;109:8. doi:10.1093/jnci/djw329

40. Wang YA, Jian JW, Hung CF, et al. Germline breast cancer susceptibility gene mutations and breast cancer outcomes. BMC Cancer. 2018;18(1):315. doi:10.1186/s12885-018-4229-5

\section{Publish your work in this journal}

Cancer Management and Research is an international, peer-reviewed open access journal focusing on cancer research and the optimal use of preventative and integrated treatment interventions to achieve improved outcomes, enhanced survival and quality of life for the cancer patient.
The manuscript management system is completely online and includes a very quick and fair peer-review system, which is all easy to use. Visit http://www.dovepress.com/testimonials.php to read real quotes from published authors. 